Simon D. Thunder

\title{
Mereological nihilism: Keeping it Simple
}

\section{Introduction}

In this paper I argue that, contra Karen Bennett, (mereological) nihilism is more ontologically parsimonious than its main rival, (mereological) universalism.

Nihilism ${ }^{1}$ is the view that there are no composite material objects - there are only simples, i.e. objects with no proper parts, which are most naturally identified with sub-atomic particles such as quarks (for brevity's sake I'll assume that all such sub-atomic particles are quarks). ${ }^{2}$ In contrast, universalists $^{3}$ posit the mereological fusion of every collection of disjoint objects. The universalist ontology is therefore populated not only by quarks, but also by composite objects such as tables, donkeys, table-donkeys, etc.

So, both the nihilist and universalist ontologies contain all of the quarks, but the universalist ontology is further bloated by composite objects. There is thus a prima facie case for nihilism being more quantitatively parsimonious than universalism because it seems to posit fewer entities (tout court), and more qualitatively parsimonious because it seems to posit fewer distinct kinds of entity (it doesn't posit composite objects). If this prima facie case can be vindicated, it's a significant result for the nihilist: ontological parsimony is almost always thought to be a theoretical virtue, so a nihilist

\footnotetext{
${ }^{1}$ Rosen \& Dorr (2002) and Sider (2013) have defended nihilism.

${ }^{2}$ I'm also going to assume that all material objects are either simples or ultimately composed of simples. I take this to be a warranted assumption because if it's false then at least some objects are gunky, in which case nihilism is false (see Sider 1993) and there'd be no point in debating its relative parsimony.

${ }^{3}$ Lewis (1986: 212-3) and Sider (2001: esp. 121-32) have defended universalism.
} 
Simon D. Thunder

victory in the quantitative and qualitative parsimony stakes gives us a defeasible reason to be nihilists.

In this paper I vindicate the prima facie case for nihilism's victory in the parsimony stakes by responding to two arguments that seek to undermine the case. I'll first (\$2) consider an argument from Karen Bennett to the effect that, on closer inspection, nihilism is no more quantitatively parsimonious than universalism. I'll argue that, contra Bennett, on even closer inspection, nihilism posits fewer entities than universalism. I'll then (§3) suggest that Bennett's reasoning can be redirected to attack the claim that nihilism is more qualitatively parsimonious than universalism. Again, I'll reject this and argue that nihilism posits fewer kinds of entity than universalism. I'll conclude (§4) that nihilism is both more quantitatively and qualitatively parsimonious than universalism.

\subsection{Bennett's argument}

Here's a brief reconstruction of Bennett's argument:

(1) Theory A is more quantitatively parsimonious than theory B iff A posits fewer entities than B.

(2) Properties are entities.

(2) is controversial, but Bennett claims that if it's false then a more complicated nominalist-friendly version of her argument invoking ideological parsimony can be made instead (2009: 64). I'll grant that she's right about this and won't dispute (2). 
Simon D. Thunder

(3) For every composite object posited by universalism, there is a perplural property (I'Il say more about these below) posited by nihilism.

This is the crucial premise. I'll elaborate on it and present Bennett's defence of it below. For now, moving on:

(4) So, nihilism and universalism posit the same number of entities.

(5) So, nihilism and universalism are equally quantitatively parsimonious. ${ }^{4}$

The argument as stated isn't valid. So Bennett must be assuming the following premise between (3) and (4), which validates the argument:

If we ignore the universalist's composite objects and the nihilist's alleged perplural properties, universalism and nihilism posit the same number of entities.

An inventory of the nihilist and universalist ontologies demonstrates the plausibility of (3.5). First, both ontologies contain the quarks. Second, both ontologies contain the singular properties of the quarks, such as having $+1 / 2$ spin. Third, both ontologies contain the plural arrangement-properties of the quarks. Plural properties are properties that are instantiated by multiple $x s$, without entailing the existence of any singular composite entity which we might call 'the multiple $x s^{\prime},{ }^{5}$ and which are non-

\footnotetext{
${ }^{4}$ Bennett hedges by claiming that the two theories merely 'come out roughly on a par' (2009: 64, my emphasis) in terms of the amount of entities they posit and that 'it is not obvious' that nihilism is more parsimonious than universalism (63). But her reasoning appears to support the unhedged conclusion, so, having made this caveat, I'Il continue to characterise her as endorsing (5).

${ }^{5}$ Bennett accepts this point (2009: 59), though see Linnebo (2003).
} 
Simon D. Thunder

distributive in that they are only instantiated by the xs collectively, not by each individual $x .{ }^{6}$ Plural arrangement-properties determine how some objects are arranged. ${ }^{7}$ Fourth, the nihilist ontology contains plural properties that don't concern the arrangement of the quarks, such as [collectively] weighing 20kg; the universalist ontology contains singular properties of composites such as weighing $20 \mathrm{~kg}$. There appears to be a one-to-one correspondence between these nihilist plural nonarrangement-properties and universalist singular properties of composites.

This inventory seems exhaustive. So I'll grant (3.5).

Bennett's argument now turns on (3). In the remainder of this section I present her defence of it.

Bennett argues $(2009: 60,64)$ that the nihilist cannot give an adequate account of the often complexly structured nature of reality with an ontology consisting only of quarks, singular properties, and plural properties. 'Complexly structured' here applies to any structure that has substructures. So consider a (putative) molecule, for example. Best science has it that molecules are made out of atoms, which (roughly speaking) are made out of quarks. Putative molecules thus have a complex structure: an overall molecular structure with atomic substructures. So putative molecules are a

\footnotetext{
${ }^{6}$ For example, if the plural property of surrounding the building is instantiated by some police officers, then it's neither the case that each police officer would instantiate this property on her own, nor that this commits us to some singular composite entity called 'the police officers'.

${ }^{7}$ One might object that the universalist doesn't need to posit plural arrangement-properties. But l'Il assume that she does, for three reasons: 1) Bennett agrees (2009: 64); 2) It's just implausible to suggest that the quarks aren't arranged: they stand in spatial relations to one another, which appears to be all that's required to be arranged; 3) To anticipate an argument I make in §3, the universalist needs to say that the quarks are arranged e.g. $F$-wise in order to explain why they compose an $F$ (rather than a $G$ ).
} 
Simon D. Thunder

good example of the bits of reality that Bennett thinks the nihilist is going to have difficulty in adequately accounting for.

Now, the nihilist usually takes herself to be able to adequately account for putative molecules (and all other putative composite objects for that matter) by adopting a strategy familiar from van Inwagen (1990: 98-114) and Rosen \& Dorr (2002). Where there appears to be a composite molecule, the nihilist claims that there are instead just some quarks arranged molecule-wise. In other words, the nihilist takes herself to be able to use the quarks and the plural arrangement-properties (in particular, the property of being arranged molecule-wise) that are already in her ontology to adequately account for putative molecules. After all, the empirical data apparently underdetermines whether there are composite molecules or just simples that instantiate being arranged moleculewise, so the nihilist account appears to be consistent with best science and therefore adequate.

But Bennett argues that, to give an adequate account of reality, the nihilist must tell a more complicated story about the way the quarks are arranged than simply saying that they are arranged molecule-wise (2009: 59-60). Simply saying that the quarks are arranged molecule-wise doesn't give an adequate account of putative molecules because it doesn't capture their complex structure and therefore isn't consistent with best science. Accounting for putative molecules by claiming that there are quarks that instantiate being arranged molecule-wise only captures the overall molecular structure of the putative molecule. It says nothing about, and therefore fails to capture, the atomic substructures, and is analogous to some ill-informed scientist claiming that the quarks only compose molecules, without first composing atoms. ${ }^{8}$

\footnotetext{
${ }^{8} \mathrm{~A}$ natural response here for the nihilist is that the atomic substructures are somehow included in what it is for the quarks to be arranged molecule-wise. But this is just to say that the predicate 'arranged molecule-wise'
} 
Simon D. Thunder

Given this, the nihilist might be tempted to say instead that the quarks instantiate being arranged atom-wise, and it's the atom-wise arrangements of quarks that instantiate being arranged moleculewise. This would allow her to capture both the overall molecular structure and the atomic substructures of the putative molecule. But of course, accepting that the atom-wise arrangements of quarks instantiate a property commits the nihilist to positing atom-wise arrangements (i.e., presumably, atoms), which she cannot accept.

So the nihilist must find some other way of capturing, or accounting for, complex structures such as that of the putative molecule. In Bennett's words, the nihilist must 'preserve compositional structure' when she gives her composite-free account of reality (60). Her ontology of quarks and plural arrangement-properties alone doesn't give her the tools she needs to do this (and the other plural properties and singular properties in her ontology aren't going to help).

Bennett concludes that the nihilist must inflate her ontology with new, complex arrangementproperties that the nihilist can say are instantiated by the quarks, thereby allowing the nihilist to capture complex structures in reality (2009: 60). I'll call these 'perplural arrangement-properties', because the bit of language that describes them is called 'perplural predication' (see Uzquiano 2004). Perplural properties are to plural properties what plural properties are to ordinary singular properties. Whilst plural properties tell us what properties groups of $x$ s have, without entailing the existence of a composite 'group of $x s^{\prime}$, perplural properties tell us what properties groups of groups of (groups of groups of... etc.) xs have, without entailing the existence of a singular composite 'group picks out a complicated property that captures both the atomic substructures and overall molecular structure, which is exactly the sort of property that, as we'll see, Bennett is trying to get the nihilist to posit here. 
Simon D. Thunder

of groups of $x s^{\prime}$. Perplural arrangement-properties allow us to capture complex structures whilst only committing us to the existence of the basic building blocks of the structures. For example, to capture the complex structure of a putative molecule, the nihilist can say that the quarks instantiate the perplural property of being arranged ((atom-wise) molecule-wise). This complex property captures how the quarks are arranged into atomic structures, which are themselves arranged into a molecular structure, but which doesn't entail the existence of atomic structures (atoms).

So the nihilist apparently must posit perplural arrangement-properties to account for complex structures in reality. And, claims Bennett, the nihilist must posit one of these perplural properties for every composite object the universalist posits (2009: 65) (for example, where the universalist posits a composite molecule, the nihilist must posit being arranged ((atom-wise) molecule-wise)). If this is right, then it follows that (3) holds.

Given that I've granted the other premises of Bennett's argument, if her defence of (3) succeeds then her conclusion that nihilism and universalism are equally quantitatively parsimonious follows. In the next subsection, however, I'll say why (3) is false and should be replaced with a different premise that generates a different conclusion: that nihilism is more quantitatively parsimonious than universalism.

\subsection{A recount}

Premise (3) of Bennett's argument (as I've reconstructed it) is false. Though I concede that the nihilist must posit perplural arrangement-properties for the reasons Bennett gives, contra Bennett the nihilist posits fewer perplural arrangement-properties than the universalist posits composite objects. 
Simon D. Thunder

My argument here will make use of the notion of first-level and higher-level composites, which I define in terms of being directly and indirectly composed by the simples respectively. So let us say that:

$X$ is directly composed by the $y$ s iff $x$ is composed by the $y$ s and there are no zs such that the zs are composed by the $y$ s and $x$ is composed by the $z$;

$X$ is indirectly composed by the $y$ iff $x$ is composed by the $y$ s but there are some $z$ s such that $x$ is composed by the zs and the zs are composed by the ys;

$X$ is a first-level composite iff $x$ is directly composed by the simples;

$X$ is a higher-level composite iff $x$ is indirectly composed by the simples.

For example, according to the universalist, molecules are higher-level composites because they're indirectly composed by quarks (i.e. the simples): a molecule is composed by the quarks, but it is also composed by the atoms which themselves are composed by the quarks. In contrast, the universalist's first-level composites are the quark-pairs, where 'quark-pair' refers to the mereological fusion of two quarks: for any quark-pair, there can be no other objects that are composed by two quarks that themselves compose the quark pair.

We can now deploy these terms to undermine Bennett's argument. To establish (3), Bennett needs the nihilist to have to posit as many perplural properties as the universalist posits composite objects, both higher-level and first-level. But the nihilist need only posit as many perplural properties as the 
Simon D. Thunder

universalist posits higher-level composite objects. This is because Bennett's argument only compels the nihilist to posit perplural properties to account for complexly structured putative composites, and the only complexly structured putative composites are the higher-level ones. Putative first-level composites have no internal substructure as they are composed directly by the simples: quark-pairs only have an overall 'quark-pair' structure, and since the quarks that (directly) compose them are simple, they have no internal substructure that needs to be captured by the nihilist with a perplural property. As such, the nihilist doesn't need to posit perplural properties to account for putative firstlevel composites. She can instead simply use quarks and merely plural arrangement-properties to account for them. Where the universalist posits a composite quark-pair, the nihilist need only posit the plural property of being arranged quark-pair-wise.

So (3) is false and should be replaced with

$\left(3^{*}\right)$ The nihilist posits fewer perplural properties than the universalist posits composite objects.

(1), (2), (3*), (3.5) and (4) together entail my conclusion:

$\left(5^{*}\right)$ Nihilism is more quantitatively parsimonious than universalism.

\section{Bennett's argument redirected}

Bennett's argument can be redirected so as to attack the claim that nihilism is more qualitatively parsimonious than universalism. Whilst universalism countenances a kind of entity that the nihilist doesn't, i.e. composite objects, Bennett's reasoning apparently demonstrates that the nihilist must in turn posit a kind of entity that the universalist doesn't, i.e. perplural properties. If this is right then the nihilist cannot claim victory in the qualitative parsimony stakes. 
Simon D. Thunder

In response, I claim that the universalist must posit perplural properties too, thus tipping the balance of qualitative parsimony back into the nihilist's favour. I have two arguments for this.

\subsection{Two Arguments}

First argument. Facts about the ways some quarks are arranged seem to depend solely on facts about the locations of the quarks, not on facts about whether the quarks compose anything or not (Brenner 2015: 1311). Since the nihilist and the universalist agree on the locations of the quarks, they ought to agree on the way the quarks are arranged (even though they disagree on whether the quarks also compose something). For the sorts of reasons I elaborated on in $\S 2.1$, the nihilist must in some cases say that the quarks are arranged ((atom-wise) molecule-wise). ${ }^{9}$ So the universalist must say so too. Thus the universalist must posit perplural properties such as being arranged ((atom-wise) molecule-wise).

Second argument. The universalist must posit perplural properties to account for what it is in virtue of which (higher-level) composite objects exist. Let me explain.

\footnotetext{
${ }^{9}$ Actually, given that the universalist's first-level composites are quark-pairs, not atoms, she must actually say something closer to 'the quarks are arranged (((quark-pair-wise) atom-wise) molecule-wise)'. Nothing turns on this wrinkle, which I'll ignore in what follows.
} 
Simon D. Thunder

Most believers in composites, including universalists, accept that composites are not fundamental, but rather exist in virtue of their parts. ${ }^{10}$ For example, the molecule is usually thought to exist in virtue of the atoms that compose it. One of the features of the in-virtue-of relation is that if $x$ exists in virtue of $y$ then facts about $y$ fix (or determine) all of the facts about $x$ (e.g. Schaffer 2009: 351). So facts about the atoms are supposed to fix all of the facts about the molecule. Furthermore, since atoms are supposed to exist in virtue of the quarks that compose them, facts about the quarks are supposed to fix all of the facts about the atoms. ${ }^{11}$

So far so unproblematic for the universalist. But there's a twist. The in-virtue-of relation is transitive (e.g. Audi 2012: §4): if $x$ exists in virtue of $y$, and y exists in virtue of $z$, then $x$ exists in virtue of $z$. If the molecule exists in virtue of the atoms, and the atoms exist in virtue of the quarks, then the

${ }^{10}$ E.g. Cameron (2014), Korman (2016: §4), Koslicki (2008: 186), and Wilson (2014) accept this more or less explicitly. Even those who don't explicitly accept it are most naturally read to be tacitly endorsing it, and the claim seems required to explain the intimate connection between composites and their parts, as demonstrated by e.g. the fact that, the parts always go wherever the whole they compose goes (see Cameron [2014] for elaboration of this point). Some believers in composites might follow Schaffer (2010) in accounting for this intimate connection by adopting priority monism, the view that composites exist in virtue of the larger composites of which they are parts, but this view is non-standard and I won't discuss it here.

${ }^{11}$ It's possible to hold that universalists should go in for a global rather than local in-virtue-of story: rather than holding, for example, that local facts about particular atoms fix the facts about the particular molecules they putatively compose, perhaps we should take the view that, globally, quark-level facts fix the atomic-level facts, and that atomic-level facts fix the molecular-level facts (see Potochnik [2010: 62-3]). But if such a view is correct my argument still demonstrates that one of the quark-level facts must be that the quarks instantiate being arranged ((atom-wise) molecule-wise), which gets me my desired conclusion. Thanks to Lina Jansson for helpful discussion on this point. 
Simon D. Thunder

molecule exists in virtue of the quarks. This implies that facts about the quarks must fix all of the facts about the molecule. Crucially, one of the facts about the molecule that must be fixed by facts about the quarks is the fact about the molecule's complex structure. Only a fact about what arrangement-property the quarks instantiate will do the trick. But what arrangement-property must the quarks instantiate to fix the complex structure of the molecule? This is essentially the same question that the nihilist was faced with in $\S 2.1$ : how to account for the putative molecule and its complex structure with only quarks and properties of the quarks? The answer is the same. Being arranged molecule-wise won’t do: as established in §2.1, this doesn’t fix the facts about the atomic substructures within the molecule. And being arranged atom-wise won't do either because it fails to fix the overall molecular structure: each group of quarks that are arranged atom-wise could be distant to the others, thus not forming an overall molecular structure at all. The only property of the quarks that fixes the fact of the molecule's complex structure is being arranged ((atom-wise) molecule-wise). So the universalist must accept that the quarks instantiate being arranged ((atomwise) molecule-wise), and must therefore posit this perplural property. ${ }^{12}$

Clearly the point generalises: for every higher-level composite that she posits, the universalist must also posit a perplural arrangement-property in order to be able to account for what it is in virtue of which that particular composite exists.

\footnotetext{
12 The universalist might object that a fact about the quarks other than a fact about what (perplural) arrangement-property they instantiate can fix the fact about the molecule's complex structure, thus allowing her to avoid positing perplural arrangement-properties. But if such a fact could be found then the nihilist could make use of it too, thus also allowing her to avoid having to posit perplural arrangement-properties to capture the putative molecule's complex structure.
} 
Simon D. Thunder

We thus have two independent arguments that demonstrate that the universalist must join the nihilist in positing perplural properties. Since the universalist also posits an extra kind of object, i.e. composite objects, her theory is less qualitatively parsimonious than the nihilist's.

\subsection{Objection: what kind of kind do you mean?}

Finally, let me address a potential objection to the foregoing argument. ${ }^{13}$

I've suggested that composite objects, simples, perplural properties, and non-perplural properties constitute distinct kinds from one another, and have used this to argue that nihilism is more qualitatively parsimonious than universalism. But one might wonder whether we could divide the world up into kinds in a different way, thereby getting different results about which theory is the more qualitatively parsimonious. For example, perhaps the relevant kinds for the purposes of qualitative parsimony comparisons are objects and properties; since nihilism and universalism both posit these, this would make the two theories come out as equally qualitatively parsimonious, even if I'm right about the universalist having to join the nihilist in positing perplural properties.

I know of no way to conclusively establish that my way of carving the world up into kinds is the right way. But, given the dialectic, I don't really need to. No matter how we decide to count kinds, my argument in $\S 3.1$ leaves the nihilist in a strong dialectical position.

\footnotetext{
${ }^{13} \mathrm{I}$ 'm grateful to an anonymous referee for pressing me to address this objection.
} 
Simon D. Thunder

This is because, if my argument in $§ 3.1$ is sound, the universalist must join the nihilist in positing perplural properties, which means that the universalist posits everything the nihilist does. So the universalist posits at least as many kinds of entity as the nihilist. But the universalist also posits composite objects. Now, on many natural and plausible ways of counting kinds, this extra commitment to composite objects brings with it a commitment to at least one extra kind of entity. If so, then my argument that nihilism is more qualitatively parsimonious than universalism goes through straightforwardly. But even if the universalist's commitment to composite objects doesn't commit her to a new kind of entity (because composite objects belong to a kind that she and the nihilist already posit), her theory is still only equally as qualitatively parsimonious as nihilism. And though this means that the nihilist has lost (or, really, tied) the qualitative parsimony battle, she has still won the ontological parsimony war. For I've already demonstrated that nihilism is more quantitatively parsimonious than universalism, and even those who doubt the importance of quantitative parsimony in theory choice ought, as Divers (1994: 388) convincingly argues, to at least regard it as a tie-breaker when trying to assess the ontological costs of two equally qualitatively parsimonious theories.

In a sense, then, little is at stake here: if I'm wrong about how to count kinds, then nihilism still ends up being at least equally as qualitatively parsimonious as universalism, which is enough to guarantee nihilism a win in the overall ontological parsimony stakes. But my way of counting kinds is natural, and consonant with the intuitive thought that a commitment to composite objects brings with it a commitment to at least one new kind of entity. So I see no reason to depart from my assumption that composite objects, simples, perplural properties, and non-perplural properties constitute distinct kinds from one another. I therefore stand by my claim that nihilism is more qualitatively parsimonious than universalism. 
Simon D. Thunder

\section{Conclusion}

I conclude that neither Bennett's argument nor the suggested redirection thereof succeed, and that nihilism is indeed more quantitatively and qualitatively parsimonious than universalism. This is significant: if, as is often supposed, ontological parsimony is a theoretical virtue, then we have a (defeasible) reason to be nihilists. ${ }^{14}$

\section{$\underline{\text { References }}$}

Audi, P. 2012. Grounding: Toward a theory of the in-virtue-of relation. The Journal of Philosophy 109: 685-711.

Bennett, K. 2009. Composition, Colocation, and Metaontology. In Metametaphysics, eds. D.

Chalmers, M. Manley and R. Wasserman, 38-76. Oxford: Oxford University Press.

Brenner, A. 2015. Mereological Nihilism and the Special Arrangement Question. Synthese 192: 1295314.

Cameron, R. 2014. Parts Generate the Whole, but they are not Identical to it. In Composition as Identity, eds. A. Cotnoir and D. Baxter, 90-110. Oxford: Oxford University Press.

Divers, J. 1994. On the Prohibitive Cost of Indiscernible Concrete Possible Worlds. Australasian Journal of Philosophy 72: 384-9

\footnotetext{
${ }^{14}$ I'm extremely grateful to Jonathan Tallant, who provided invaluable comments on several drafts of this paper, and to the (AHRC-funded) Midlands3Cities DTP, who are funding my postgraduate study.
} 
Simon D. Thunder

Korman, D. 2016. Ordinary Objects. The Stanford Encyclopedia of Philosophy (Spring 2016 edition), ed. E. Zalta. URL = <plato.stanford.edu/archives/spr2016/entries/ordinary-objects/>.

Koslicki, K. 2008. The Structure of Objects. Oxford: Oxford University Press.

Lewis, D. 1986. On the Plurality of Worlds. Oxford: Blackwell.

Linnebo, Ø. 2003. Plural Quantification Exposed. Noûs 37: 71-92.

Potochnik, A. 2010. Levels of Explanation Reconceived. Philosophy of Science 77: 59-72.

Rosen, G. and Dorr, C. 2002. Composition as a Fiction. In The Blackwell Guide to Metaphysics, ed. R. Gale, 151-174. Oxford: Blackwell.

Schaffer, J. 2009. On What Grounds What. In Metametaphysics, eds. D. Chalmers, M. Manley and R. Wasserman, 347-83. Oxford: Oxford University Press.

Schaffer, J. 2010. Monism: The Priority of the Whole. Philosophical Review 119: 341-76.

Sider, T. 1993. Van Inwagen and the Possibility of Gunk. Analysis 53: 286-9.

Sider, T. 2001. Four Dimensionalism. Oxford: Oxford University Press.

Sider, T. 2013. Against Parthood. In Oxford Studies in Metaphysics 8, eds K. Bennett and D.

Zimmerman, 237-93. Oxford: Oxford University Press.

Uzquiano, G. 2004. Plurals and Simples. The Monist 87: 429-51.

Van Inwagen, P. 1990. Material Beings. Ithaca: Cornell University Press.

Wilson, J. 2014. No Work for a Theory of Grounding. Inquiry 57: 535-79. 